Other applications were also covered: molecular dissociation, atomic collisions in solids, super heavy element physics, spectroscopy of biomolecules.

M.J. Seaton reported on some astrophysical spectra observed in the ultraviolet region. Results obtained with the International Ultraviolet Explorer satellite (IUE) during the past $4 \frac{1}{2}$ years were reviewed. For long the attention of spectroscopists has been attracted by astronomical objects of low density because they contain many "forbidden" lines difficult to produce in the laboratory. Conversely astrophysicists obtain abundances of the chemical elements from quantitative spectrum analysis, notably $\mathrm{C}, \mathrm{N}$ and $\mathrm{O}$ which are of interest because $\mathrm{N}$ is produced from $\mathrm{C}$ and $\mathrm{O}$ in the course of hydrogen burning through the $\mathrm{CNO}$ cycle, whereas $\mathrm{C}$ is produced through helium burning in the triple- $\alpha$ process. The forbidden and resonance lines are excited by electron impacts and many have been observed which were not expected, because of their large excitation potentials.

Relativistic effects in atomic structure calculations were the subject of the invited talk of A. Hibbert who discussed recent progress in two types of calculation. Such effects can be treated as a perturbation on non-relativistic calculations in light and some heavier atoms. A fully relativistic treatment based on the Dirac or Dirac-Fock equation is necessary in heavy atoms. In this case the inclusion of core polarization effects has been considered. He also discussed some of the difficulties of obtaining accurate results.

Special sessions were held in memory of Professor D. Jackson and Dr. Erna Meinders - a former secretary of EGAS. Addresses were given in their honour by respectively A.P. Thorne and P.F.A. Klinkenberg.

In addition to invited and contributed papers, the tradition of round-table discussions was continued.

\section{Eusebio Bernabeu}

\title{
Amendments to the Constitution and By-laws Agreed by Council in Copenhagen
}

\section{ARTICLE 16}

The Council shall be composed in the following way:

a) as before / b) as before / c) as before /

d) delegates or representatives elected in accordance with the by-laws, by Associate Members mentioned in Article 6, as follows:

less than $50 \quad$ Associate Members: 3 representatives
$50-100$ Associate Members: 4 representatives
$100-150$ Associate Members: 5 representatives

\section{RULE 4}

$100-150$ Associate Members: 5 representatives

Honorary Members shall have the same right as Ordinary Members to attend meetings and subscribe to the publications of the Society. They shall not have the right to vote and they shall not be eligible for service on the Council. Admission to Honorary Membership shall be decided by the Council. The total number of Honorary Members at any one time shall not exceed fifty.

RULE 5

Each Associate Member shall have the right, as for an Ordinary Member, to send one representative to meetings and take out one subscription to the publications of the Society. Associate Members shall be represented in Council according to Article 16d) of the Constitution. Admission to Associate Membership shall be decided by the Council.

\section{RULE 18}

a) former RULE 18 is now 18 a)

b) former RULE 19 becomes now 18b)

RULE 19

Representatives on the Council of Associate Members - Constitution Article 6 - shall be elected by ballot from a list, provided by the Secretariat, of all nominations of individual candidates received from the Associate Members before 1 January of the year of the election. The ballot returns, with candidates arranged in order of decreasing number of votes obtained, then provide the names of that category of Council members, in the number required by Article $16 \mathrm{~d}$ ) of the Constitution - and also the names for those who may be needed later on to fill casual vacancies for unexpired term - always counting down the list, in the direction of decreasing strength of ballot votes received.

RULE 34

Any decision to change the value of the unit fee, shall be supported by three out of four votes cast. In this case the entitlement of votes of the members of Council shall be on the basis of the total units assessed under Rule 35 of these By-laws. Proxy voting shall be permitted.

Any proposal by the Executive Committee to increase the unit fee shall be submitted in writing to all Ordinary Members and Fellows at least three months before the Council is to meet to decide the matter.

The Divisional Chairmen and the representatives of Associate Members have no voting right for a change in the value of the unit fee.

\section{Delegates of Individual Members}

Following the postal ballot of the Individual Members of EPS, the following three new delegates to Council have been elected:

J. Ernest, Marcoussis, F

V. Heine, Cambridge, UK

F. Janouch, Stockholm, S with as first alternate:

H. Lotsch, Heidelberg, D
Delegates completing their three year term were M. Balkanski, A. Messiah and E.A. Müller. Delegates continuing are:

K. Bethge, Frankfurt/Main

J. Devreese, Antwerp

$\mathrm{H}$. de Waard, Groningen

F. Fumi, Genoa

J. Niederle, Prague

T. Riste, Kjeller
Europhysics News is the official joumal of the European Physical Society which comprises 29 National Socie ties, Academies and Groups, over 3000 Individua Members and 62 Associate Members. Governing bo dies of EPS are the General Meeting, Council and an elected Executive Committee responsible for detailed policy. EPS promotes the collaboration of physicists throughout Europe, organising and harmonising conferences, and promotes international exchanges in physics including participation in research and teaching activities abroad and attendance at schools. EPS publishes in addition to EN, Europhysics Conference blishes in addition to EN, Europhysics Conference
Abstracts, E. Ed. News and, in collaboration with The Institute of Physics (UK), the European Journal of Physics. Individual Members receive EN free of charge (price to institutions: Sw.Fr. $82 .-/ a$ ), rebates on the price of many publications and on conference fees. An nual EPS membership fee for Individual Members who belong to one of the EPS member societies for 1983 is Sw.Fr. 40.-; for independent members: Sw.Fr. 120.-

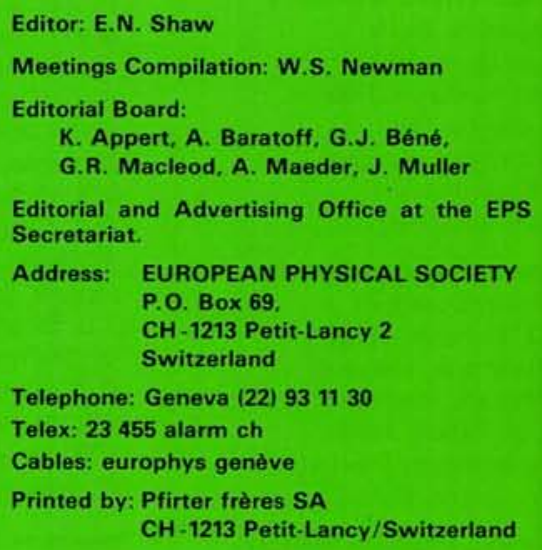

